\title{
Expression of Two Different Tachykinin Receptors in Xenopus Oocytes by Exogenous mRNAs
}

\author{
Y. Harada, ${ }^{1, a}$ T. Takahashi,, ${ }^{1}$ M. Kuno, ${ }^{1}$ K. Nakayama, ${ }^{2}$ Y. Masu, ${ }^{2}$ and S. Nakanishi ${ }^{2}$ \\ 'Department of Physiology and Institute for Immunology, Kyoto University Faculty of Medicine, Kyoto 606, Japan
}

Three tachykinins, substance $P$ (SP), neurokinin A (NKA), and neurokinin $B$ (NKB), have been isolated from the mammalian nervous system. In accordance with the presence of multiple tachykinins, the existence of multiple tachykinin receptors has been suggested. These receptors differ in binding specificities for different tachykinins. However, it is not known whether these receptors are indeed made of different molecules or whether the same receptor molecule undergoes posttranslational modification at different destination tissues, thereby altering its binding specificity. We examined whether mRNAs isolated from different tissues may synthesize different types of tachykinin receptors in the same expression system. For this purpose, Xenopus oocytes were injected with poly (A)+ RNAs extracted from rat brain or bovine stomach, and their responses to different tachykinins were examined under voltage-clamp. On the basis of potency ranking of 6 tachykinin agonists, the receptor induced by rat brain mRNA was found to correspond to a tachykinin receptor subtype currently classified as the NK-1 (SP-P) receptor, whereas that synthesized by bovine stomach mRNA corresponded to the NK-2 (NK-A) receptor. Thus, each of the 2 receptors can be induced in the same expression system, depending upon the source of exogenous mRNA injected. Therefore, the difference in the nature of the 2 receptors does not seem to be due to the possible posttranslational modification alone. However, the ionic mechanisms underlying activation of the 2 receptors translated in oocytes were similar. It is likely that activation of the 2 receptors uses the same internal mediator in oocytes.

Substance $\mathrm{P}(\mathrm{SP})$ is a member of the tachykinin family (Erspamer, 1981) and one of the peptide neurotransmitter candidates in the mammalian central nervous system (Hökfelt et al., 1975; Otsuka et al., 1975; Takahashi and Otsuka, 1975). Recently, 2 additional tachykinins, neurokinin A (NKA; also known as substance $\mathrm{K}$ ) and neurokinin $\mathrm{B}$ (NKB; also known as neuromedin $\mathrm{K}$ ), have been isolated from the mammalian nervous system (Kangawa et al., 1983; Kimura et al., 1983; Nawa et al., 1983). Nawa et al. (1983) have elucidated the primary structure of 2 types of SP precursors (preprotachykinins) in the bovine brain. One of them ( $\alpha$ type) contains a single SP sequence, whereas

Received Dec. 17, 1986; revised Mar. 17, 1987; accepted Apr. 23, 1987.

This work was supported by research grants from the Ministry of Education, Science and Culture of Japan.

Correspondence should be addressed to Motoy Kuno at the above address.

a Present address: Department of Physiology, Nippon Medical School, Tokyo 113 , Japan.

Copyright (c) 1987 Society for Neuroscience $0270-6474 / 87 / 103265-09 \$ 02.00 / 0$ $\beta$-preprotachykinin contains an NKA sequence in addition to an SP sequence (Nawa et al., 1983; see also Harmer et al., 1986). While the mRNAs coding for the 2 preprotachykinins are produced from a single gene, their expression is regulated diffcrentially in a tissue-specific manner (Nawa et al., 1984b). Thus, $\alpha$-preprotachykinin forming SP is preferentially synthesized in the brain, whereas in peripheral tissues, including the thyroid and digestive organs, $\beta$-preprotachykinin containing SP and NKA is predominantly produced (Nawa et al., 1984b; Nakanishi, 1986). This may account for differential distributions of the 2 peptides among different tissues.

In accordance with the presence of multiple tachykinins, the existence of multiple tachykinin receptors has been suggested (Lee et al., 1982; Buck et al., 1984; Hunter and Maggio, 1984; Nawa et al., 1984a; Laufer et al., 1985; Lee et al., 1986). This suggestion is based on the rank order of pharmacological potency or binding specificities for different tachykinins. If the receptor specific for each endogenous tachykinin is present, mRNAs encoding the receptors for SP and NKA may also be synthcsizcd differentially for the brain and the peripheral tissues. Alternatively, it is possible that the same tachykinin receptor molecule may undergo posttranslational modification in a tissue-specific manner, thereby altering its binding specificity. In order to test these possibilities, we have examined whether mRNAs isolated from different tissues may synthesize different types of tachykinin receptors in the same expression system.

The injection of appropriate exogenous mRNA into Xenopus oocytes is known to induce functional, foreign receptor-channel complexes in the membrane (Barnard et al., 1982). In the present study, Xenopus oocytes were injected with mRNAs extracted from the rat brain or the bovine stomach, and their responses to the application of different tachykinins were subsequently examined electrophysiologically. The results show that 2 different types of tachykinin receptors can be expressed in injected oocytes, and that the expression of the 2 types of receptors depends on the type of tissue from which mRNA is extracted for the injection. However, the ionic mechanisms underlying activation of the 2 receptors translated in oocytes were similar. A preliminary account of parts of this work has appeared (Harada et al., 1986).

\section{Materials and Methods}

Preparation of poly $(A)^{+} R N A$. The rat brain or the bovine stomach was pulverized in liquid nitrogen, homogenized in a solution of $4 \mathrm{M}$ guanidinium thiocyanate plus $0.1 \mathrm{M}$ 2-mercaptoethanol and centrifuged at $100,000 \times g$ for $16 \mathrm{hr}$ through a cushion of $5.7 \mathrm{M} \mathrm{CsCl}$ at $15^{\circ} \mathrm{C}$ (Chirgwin et al., 1979). The total RNA so extracted was passed through an oligo(dT)cellulose column to isolate poly(A)+ RNA (Aviv and Leder, 1972). As previously reported (Gundersen et al., 1983), oocytes injected with poly $(\mathrm{A})^{+} \mathrm{RNA}$ extracted from rat brain responded to the application of 
5-HT. However, their responses to SP were inconsistent or too small to analyze in detail (Parker et al., 1986). To improve the responsiveness to $\mathrm{SP}$, poly(A)+ RNA isolated from rat brain was further fractionated by sucrose density-gradient centrifugation (Sumikawa et al., 1984a, b; Parker et al., 1986), and the most effective fraction was selected for the microinjection. Of the 3 fractions divided by sedimentation velocity, the middle fraction was found to be most effective in inducing SP responses following microinjection. This fraction corresponded to mRNA, with sedimentation coefficients ranging from 20 to $26 \mathrm{~S}$, and with the estimated size between 2.4 and $4.0 \mathrm{kbase}$. The results for SP responses induced by rat brain mRNA were obtained from oocytes injected with this fraction, unless otherwise specified.

Responses to SP or NKA were readily elicited in oocytes injected with mRNA extracted from the bovine stomach. Therefore, no further fractionation was attempted for this mRNA sample.

Microinjections into oocytes. Adult female frogs, Xenopus laevis, were anesthetized with ice. By abdominal incision, a small piece of ovary was removed and placed in sterile Barth's medium (Barth and Barth, $1959)$ with added gentamicin $(0.1 \mathrm{mg} / \mathrm{ml})$ and mycostatin $(50 \mathrm{U} / \mathrm{ml})$. The wound was closed, and the ovary of the same animal was used repeatedly for subsequent experiments (Kusano et al., 1982). Individual oocytes were isolated from the piece of ovary by cutting the connecting epithelial layer, and were incubated for $1 \mathrm{~d}$ at $19^{\circ} \mathrm{C}$ before microinjection. Frozen aliquots of previously extracted mRNA, stored at a concentration of $2 \mu \mathrm{g} / \mu \mathrm{l}$ diluted with water, were thawed and loaded into a glass pipette with a tip diameter of about $35 \mu \mathrm{m}$. Microinjections into individual oocytes were made by pressure through the pipette. The amount of mRNA injected was approximately $40 \mathrm{ng} /$ oocyte. Injected oocytes were incubated again in sterile Barth's solution for 3-5 d at $19^{\circ} \mathrm{C}$ before electrophysiological observation.

Electrophysiology. The follicle layer of each oocyte was removed with Dumont forceps. The oocyte was then placed in a recording chamber with a volume of about $0.4 \mathrm{ml}$ and superfused with saline solution at the rate of $2.5 \mathrm{ml} / \mathrm{min}$. Most experiments were carried out with Ringer's solution of the following composition (mM): $\mathrm{NaCl}, 115 ; \mathrm{KCl}, 2.5 ; \mathrm{CaCl}_{2}$, 1.8 ; HEPES, 5 (pH adjusted to 7.4 by $\mathrm{NaOH}$ ) or Tris, 5 ( $\mathrm{pH}$ adjusted to 7.2 by $\mathrm{HCl}$ ). Two glass microelectrodes filled with $4 \mathrm{M} \mathrm{K}$ acetate were inserted into an oocyte, and the membrane potential was clamped at the desired level $(-50$ or $0 \mathrm{mV})$. Whole-cell currents were then recorded under voltage-clamp in response to the bath-application of different tachykinins or 5-HT. The drug dissolved in the perfusate was applied for $40 \mathrm{sec}$. Under certain conditions, once the oocyte had responded to a drug, it failed to respond to subsequent applications. Therefore, reversal potentials of the drug-induced responses were determined by the ramp voltage-clamp device (Dascal et al., 1984). For this purpose, the membrane potential was initially clamped at $-50 \mathrm{mV}$, and a ramp command potential was superimposed so as to change the holding potential to a range from 0 to $-110 \mathrm{mV}$, with a slope of $150 \mathrm{mV} / \mathrm{sec}$ (Fig. $6 A$ ). The "ramp clamp" was executed before drug application and during the drug response. The reversal potential was estimated from the point at which the 2 current-voltage (I-V) curves crossed (Fig. $6 B$, arrowhead).

For studies on ionic mechanisms, the ionic composition of the perfusate was modified. The details of ionic substitutes are given in the appropriate section of Results. The recording chamber was connected to the virtual ground with an agar bridge containing Ringer's solution. Therefore, when the same oocyte was superfused with different solutions, the intracellular electrode was withdrawn and reinserted upon the exchange of solutions in order to correct a shift of the bath potential. The experiments were carried out at room temperature $\left(19-25^{\circ} \mathrm{C}\right)$.

\section{Results}

Characteristics of tachykinin receptors induced by brain $m R N A$

As illustrated in Figure $1 A$, oocytes injected with rat brain mRNA showed an inward current in response to SP at a holding potential of $-50 \mathrm{mV}$. Out of 22 injected oocytes systematically examined at a holding potential of $-50 \mathrm{mV}$ in Ringer's solution after a 3-d incubation, 14 (64\%) responded to SP at a concentration of $4 \mu \mathrm{M}$. The mean latency of the response was $23 \pm 8$ (SD) sec, including the "dead-space time" of the perfusion system (approximately $14 \mathrm{sec}$ ), and the response lasted on the average, for $109 \pm 50 \mathrm{sec}$. The mean peak inward current of the 14 responsive oocytes was $136 \pm 100 \mathrm{nA}$.

The oocyte injected with the same fraction of rat brain mRNA also responded to 5-HT (Fig. $1 B$ ). It has been reported that endogenous 5-HT (Kusano et al., 1982) and SP (Miledi and Sumikawa, 1982) receptors may be present in the oocyte membrane on rare occasions. In the present study, 2 noninjected oocytes obtained from a particular frog indeed responded to 5-HT as well as to SP. However, none of the noninjected oocytes $(n>50)$ isolated from other frogs showed any response to the application of 5-HT or SP. In order to examine whether 5-HT or SP receptors can be synthesized in oocytes by translation of exogenous mRNA, oocytes sampled from 3 different frogs were incubated with actinomycin D $(50 \mu \mathrm{g} / \mathrm{ml}$; Gundersen et al., 1983) for 5-6 d from the day of isolation to prevent transcription. Microinjections to these oocytes were made on the second day after isolation, and the responses were examined 4-5 d later. Out of 60 oocytes injected with the middle fraction (20-26 S) of rat brain mRNA, $36(60 \%)$ responded to SP, and $50(83 \%)$ responded to 5 -HT. In contrast, noninjected oocytes $(n=13)$ or those injected with water $(n=20)$ or with a slowly sedimentating fraction $(<20 \mathrm{~S})$ of rat brain mRNA $(n=20)$ failed to respond to SP or 5-HT. Thus, the expression of the receptor appears to depend upon the injection of a particular fraction of the mRNA sample. Therefore, it is concluded that functional SP or 5-HT receptors can be expressed in oocytes by translation of exogenous, specific mRNA.

In a given oocyte injected with rat brain mRNA, the response to 5-HT could be elicited repeatedly (Fig. $1 D$; see also Gundersen et al., 1983). However, once the oocyte had responded to SP, it consistently failed to respond to the second application of SP (Figs. $1 C ; 3, A, B$ ) even when the second trial was made more than $30 \mathrm{~min}$ after the first application (Parker et al., 1986). Also, the sensitivity of injected oocytes to SP varied considerably from one group of oocytes to another. In a later stage of the present study, we found that the expression of SP receptors became more efficient when the oocytes were incubated for 5 instead of $3 \mathrm{~d}$ after the injection. Often, after $5 \mathrm{~d}$ incubation, all the injected oocytes responded to SP (see below).

\section{Characteristics of tachykinin receptors induced by stomach $m R N A$}

Oocytes injected with bovine stomach $\mathrm{mRNA}$ rarely responded to the application of 5-HT, but the majority of them showed responses to SP or NKA. The SP or NKA response was again an inward current at a holding potential of $-50 \mathrm{mV}$ (Fig. 2). However, the tachykinin responses observed in these oocytes differed from those seen in oocytes injected with rat brain mRNA in 2 respects. First, both SP and NKA responses could be elicited repeatedly in the same oocyte (Figs. 2,4). Second, NKA was clearly more potent than SP (Figs. 2, 4).

The tachykinin receptors induced by bovine stomach mRNA were characterized mainly by the application of NKA. Out of 20 injected oocytes examined at a holding potential of $-50 \mathrm{mV}$ in Ringer's solution after $3 \mathrm{~d}$ incubation, 17 (85\%) responded to NKA at a concentration of $4 \mu \mathrm{M}$. The peak current of the NKA response was, on the average, $140 \pm 89$ (SD) $\mathrm{nA}(n=$ 17). The mean latency of the response was $41 \pm 18 \mathrm{sec}$ (including the dead-space time; see above). This was significantly ( $p<$ $0.001)$ longer than the mean response latency for the tachykinin receptors induced by rat brain mRNA. The duration of the NKA response $(190 \pm 81 \mathrm{sec})$ was also significantly $(p<0.01)$ longer than that measured in oocytes injected with rat brain mRNA 
A
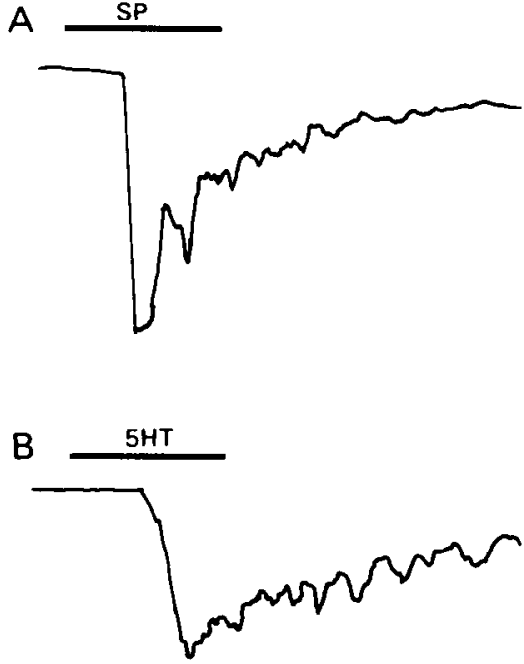
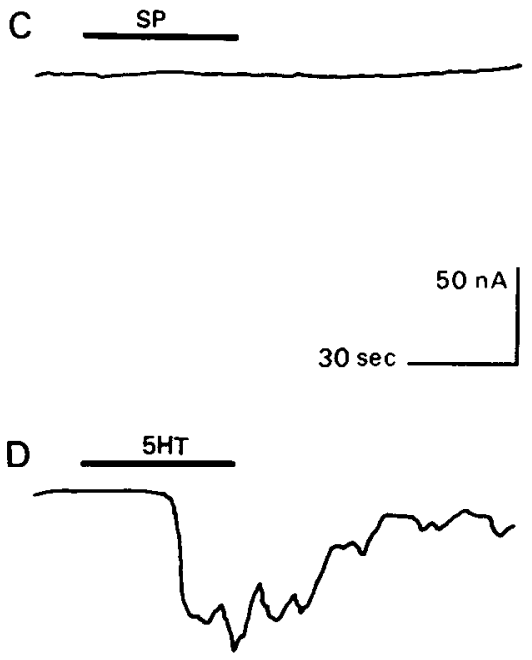

Figure 1. Responses of an oocyte injected with rat brain mRNA to the application of SP $(4 \mu \mathrm{M})$ or 5-HT $(0.1 \mu \mathrm{M})$ recorded at a holding potential of -50 $\mathrm{mV}$ in Ringer's solution. Downward deflections correspond to inward membrane currents. The drugs were applied at an interval of about $5 \mathrm{~min}$ in the order $A$ to $D$. Note that the oocyte failed to respond to the second SP application (C), while the second 5-HT application $(D)$ was still effective. Oocyte incubated for $3 \mathrm{~d}$ after the microinjection. (see Fig. 5). This behavior is similar to the prolonged responses with a delayed onset produced by tachykinins in the rat duodenum (Nawa et al., 1984a), where a tachykinin receptor subtype, the NK-2 (also known as NK-A) receptor, is predominant (Buck et al., 1984).

\section{Rank order of tachykinin potencies}

At present, 3 subtypes of tachykinin receptors have been classified (Buck et al., 1984; Laufer et al., 1985; Quirion, 1985; Lee et al., 1986). We have examined whether the 2 different types of tachykinin receptors expressed in oocytes injected with rat brain or stomach mRNA might correspond to the currently classified subtypes in the potency rank order of tachykinins.

Oocytes injected with rat brain mRNA were incubated for 5 $\mathrm{d}$ to increase their responsiveness to tachykinins. Also, the tachykinin responses were recorded as an outward current at a holding potential of $0 \mathrm{mV}$ to enhance the response magnitude (see below). Under these conditions, all of the 18 injected oocytes prepared from 2 different frogs responded to SP at concentrations of $0.1-0.4 \mu \mathrm{M}$. In these oocytes, the application of SP following the initial SP (Fig. $3 A$ ) or physalaemin (PHY; Fig. $3 B$ ) response again failed to elicit any response. However, when SP was applied after kassinin (KAS; Fig. $3 C$ ) or NKB (Fig. $3 D$ ), the second SP response was larger than the first KAS or NKB response. Thus, the potency of KAS or NKB was clearly lower than that of SP in oocytes injected with rat brain mRNA.

For potency measurements, 6 different tachykinins were ap- plied at a concentration of $0.4 \mu \mathrm{M}$. For each tachykinin, 4-7 injected oocytes obtained from the same frog were examined, and the response size was measured in terms of its area. The same procedure was then repeated for injected oocytes prepared from another frog. The potencies of the 6 tachykinins were evaluated from the mean response sizes of the 2 series of observations. This gave the following rank order (potencies relative to that of PHY, \pm SEM in parentheses): $\mathrm{PHY}(1.0) \geq \mathrm{SP}(0.94 \pm$ $0.23)>\mathrm{NKA}(0.65 \pm 0.05)=$ eledoisin $(\mathrm{ELE} ; 0.65 \pm 0.17)>$ $\operatorname{KAS}(0.46 \pm 0.16)>\mathrm{NKB}(0.09 \pm 0.01)$. This generally agreed with the rank order previously reported for the PHY subtype of tachykinin receptor (NK-1, also known as SP-P; Buck et al., 1984; Quirion, 1985; Lee et al., 1986).

As illustrated in Figure 3, the initial application of SP (Fig. $3 A$ ) or PHY (Fig. $3 B$ ) causes a failure of the response to the second application of SP, showing "desensitization" or "tachyphylactic" effects. These effects appear to be less prominent when weak agonists (KAS or NKB; Fig. 3, $C, D$ ) are applied in the first trial. If this desensitization or tachypilylactic process is initiated soon after the onset of the tachykinin response, the response size may not be directly correlated with the dose employed. When the applied agonist concentration was reduced from 0.4 to $0.1 \mu \mathrm{M}$ in one batch of injected oocytes, the magnitude of responses to ELE, KAS, or NKB decreased by about $50 \%$. In contrast, the responses to $\mathrm{PHY}, \mathrm{SP}$, or NKA became a few times larger in the low dose $(0.1 \mu \mathrm{M})$ than in the high dose $(0.4 \mu \mathrm{M})$. Thus, the latter 3 agonists seem to be highly potent

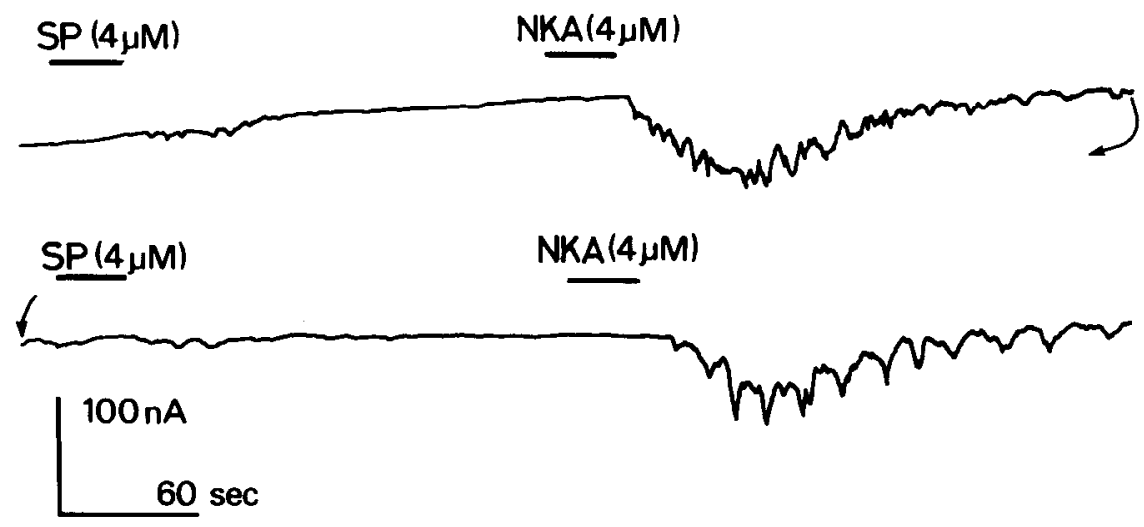

Figure 2. Responses of an oocyte injected with bovine stomach mRNA to the application of SP $(4 \mu \mathrm{M})$ or NKA (4 $\mu \mathrm{M})$ recorded at a holding potential of $-50 \mathrm{mV}$ in Ringer's solution. Downward deflections correspond to inward membrane currents. Upper and lower traces are a continuous recording. Oocyte incubated for $3 \mathrm{~d}$ after the microinjection. 
Figure 3. Responses of oocytes injected with rat brain mRNA to different tachykinins recorded at a holding potential of $0 \mathrm{mV}$ in Ringer's solution. Upward deflections correspond to outward membrane currents. $A-D$, From 4 different oocytes incubated for $5 \mathrm{~d}$ after the microinjection. For each oocyte, the drug applications were made twice at an interval of about $5 \mathrm{~min}$. Every drug was given at $0.4 \mu \mathrm{M}$.
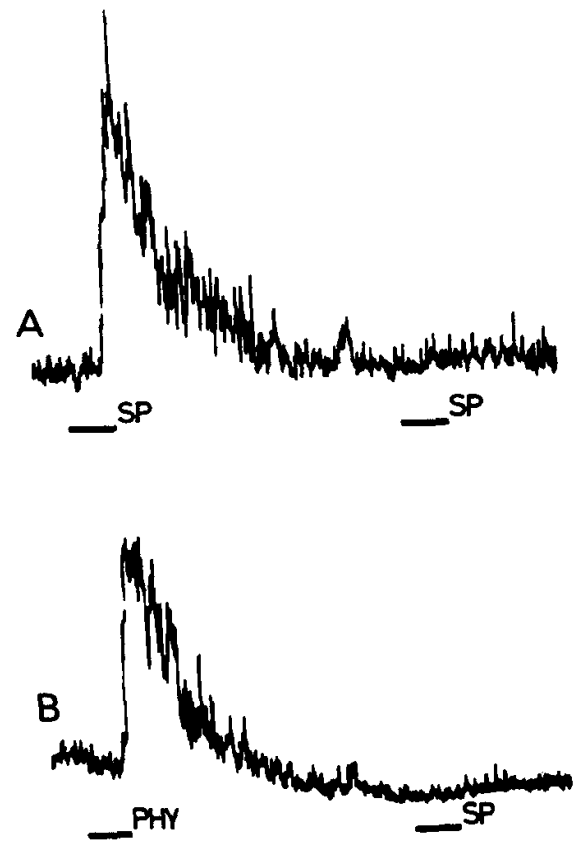
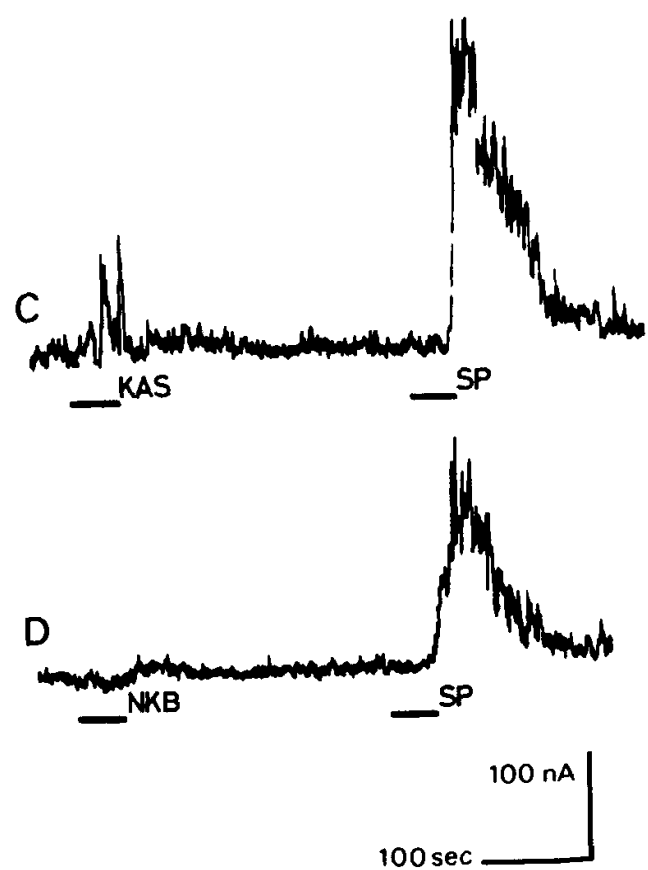

not only in eliciting tachykinin responses, but also in producing desensitization or tachyphylactic effects, thereby curtailing their full responses at high concentrations. Taking this possibility into consideration, the tachykinin potencies were again measured at a concentration of $0.1 \mu \mathrm{M}(n=4-7)$. The rank order in this series was PHY $(1.0)>\operatorname{SP}(0.74 \pm 0.17)>\mathrm{NKA}(0.64 \pm$
$0.15)>\operatorname{ELE}(0.16 \pm 0.04) \geq \operatorname{KAS}(0.15 \pm 0.05)>\mathrm{NKB}$ $(0.07 \pm 0.009)$. Thus, the general trend in rank order remained unchanged, but the difference in potency among different tachykinins became clearer at low doses. Since the rank order was determined only at 2 concentration levels, instead of using a full dose-response curve, the quantitative differences in potency
Figure 4. Responses of oocytes injected with bovine stomach mRNA to different tachykinins recorded at a holding potential of $0 \mathrm{mV}$ in Ringer's solution. Upward deflections correspond to outward currents. $A-E$, From 5 different oocytes incubated for $3 \mathrm{~d}$ after the microinjection. For each oocyte, the drug applications were made twice at an interval of about $5 \mathrm{~min}$. Every drug was given at $0.4 \mu \mathrm{M}$, except for SP in $D$ and NKB in $E$, which were given at $1 \mu \mathrm{M}$. Current calibration, 200 $\mathrm{nA}(B)$ and $100 \mathrm{nA}$ (other records).
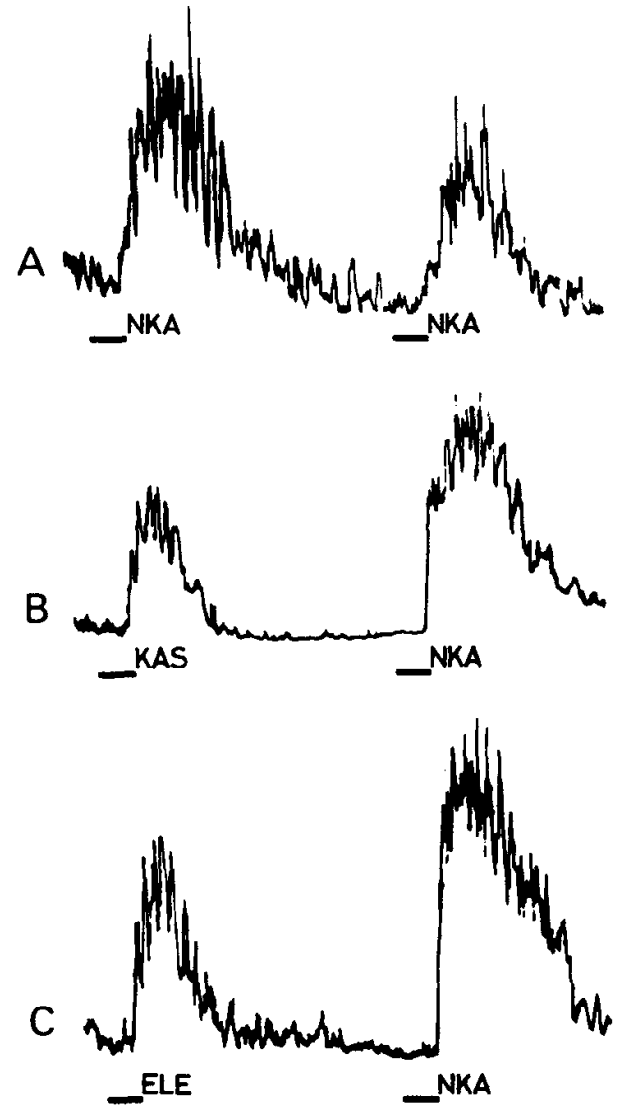

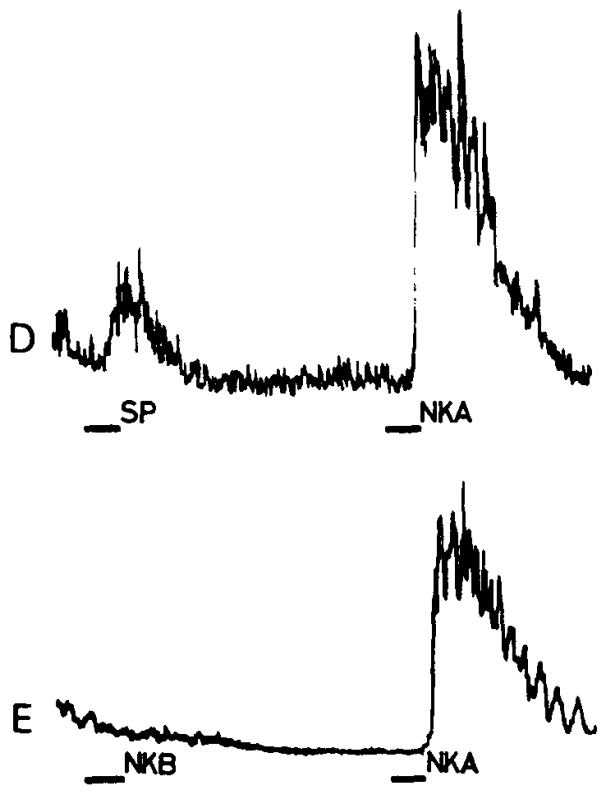

$100-200 \mathrm{nA}$
$100 \mathrm{sec}$ 
might not be reliable. However, the coincidence in rank order measured at the 2 doses does not seem to be fortuitous.

The tachykinin potencies were similarly measured for oocytes injected with bovine stomach mRNA. While these oocytes could respond to multiple applications of tachykinins, the second NKA response was usually smaller than the first (Fig. 4A). However, the first response evoked by the application of other tachykinins was consistently smaller than the response to NKA applied in the second trial (Fig. 4, $B-E$ ). Thus, NKA was clearly most potent for oocytes injected with stomach mRNA. Also, the application of PHY, SP, and NKB produced consistent responses only at doses above $1 \mu \mathrm{M}$ (Fig. $4, D, E$ ), whereas other tachykinins were effective at $0.4 \mu \mathrm{M}$ (Fig. $4, A-C$ ). Therefore, it seems clear that PHY, SP, and NKB belong to the least potent group for the receptors expressed in these oocytes. The mean potencies of different tachykinins ( $n=3-5)$ were quantified by comparing their response areas with that of the NKA response evoked in the second trial (Fig. 4). The resultant rank order was as follows: NKA $(1.0)>\operatorname{KAS}(0.46 \pm 0.11)>\operatorname{ELE}(0.28 \pm 0.05)>$ PHY $(0.15 \pm 0.08)>\mathrm{SP}(0.09 \pm 0.02)>\mathrm{NKB}(0.005 \pm 0.006)$. This rank order is markedly different from that observed for oocytes injected with rat brain mRNA, but is similar to the rank order reported for the NK-2 subtype of tachykinin receptor (Buck et al., 1984; Quirion, 1985; Lee et al., 1986).

One could argue that the initial application of other tachykinins may produce some facilitatory effect on the response to NKA applied in the second trial. This possibility is unlikely, since the same rank order was observed when their potencies were evaluated from the mean areas of all the tachykinin responses evoked by single applications. In another series of experiments, the tachykinin potencies were measured at a concentration of $4 \mu \mathrm{M}$, instead of $0.4 \mu \mathrm{M}$. Again, the same rank order, with similar potency differences, was ohserved. This suggests that the desensitization effect, as observed in oocytes injected with brain mRNA, does not significantly affect the size of tachykinin responses evoked in oocytes injected with stomach mRNA. In fact, the magnitude of the response to NKA, examined at concentrations of $0.04-4 \mu \mathrm{M}$ in the same oocyte injected with stomach mRNA, showed a dose-dependent increase.

\section{Ionic mechanisms underlying tachykinin responses}

As shown in Figures $1 A$ and 2, the tachykinin response showed an inward current at a holding potential of $-50 \mathrm{mV}$. When the membrane potential was clamped at $0 \mathrm{mV}$, the application of tachykinins produced an outward current in oocytes injected with rat brain mRNA (Fig. $5 A$ ) or bovine stomach mRNA (Fig. $5 B$ ). Also, when the holding potential was repcatedly altered by constant hyperpolarizing command pulses (Fig. 5, $A, B$, upper traces), there was a clear increase in the membrane conductance during the tachykinin response (Fig. 5, $A, B$, lower traces). Thus, the tachykinin response appears to be associated with an increase in membrane permeability to some particular ion(s).

In an example illustrated in Figure 6, an oocyte injected with rat brain mRNA was initially clamped at $-50 \mathrm{mV}$, and a ramp command potential (Fig. $6 \mathrm{~A}$ ) was superimposed once before the application of SP. This produced initial outward currents during the depolarizing phase, followed by inward currents during the hyperpolarizing phase, showing an I-V curve, illustrated in Figure $6 B$ (control). When an inward current of about $150 \mathrm{nA}$ was elicited in response to $\mathrm{SP}(4 \mu \mathrm{M})$ at a holding potential of -50 $\mathrm{mV}$, the same ramp command potential was again applied. The resultant outward and inward currents (Fig. 6B, SP) were greater
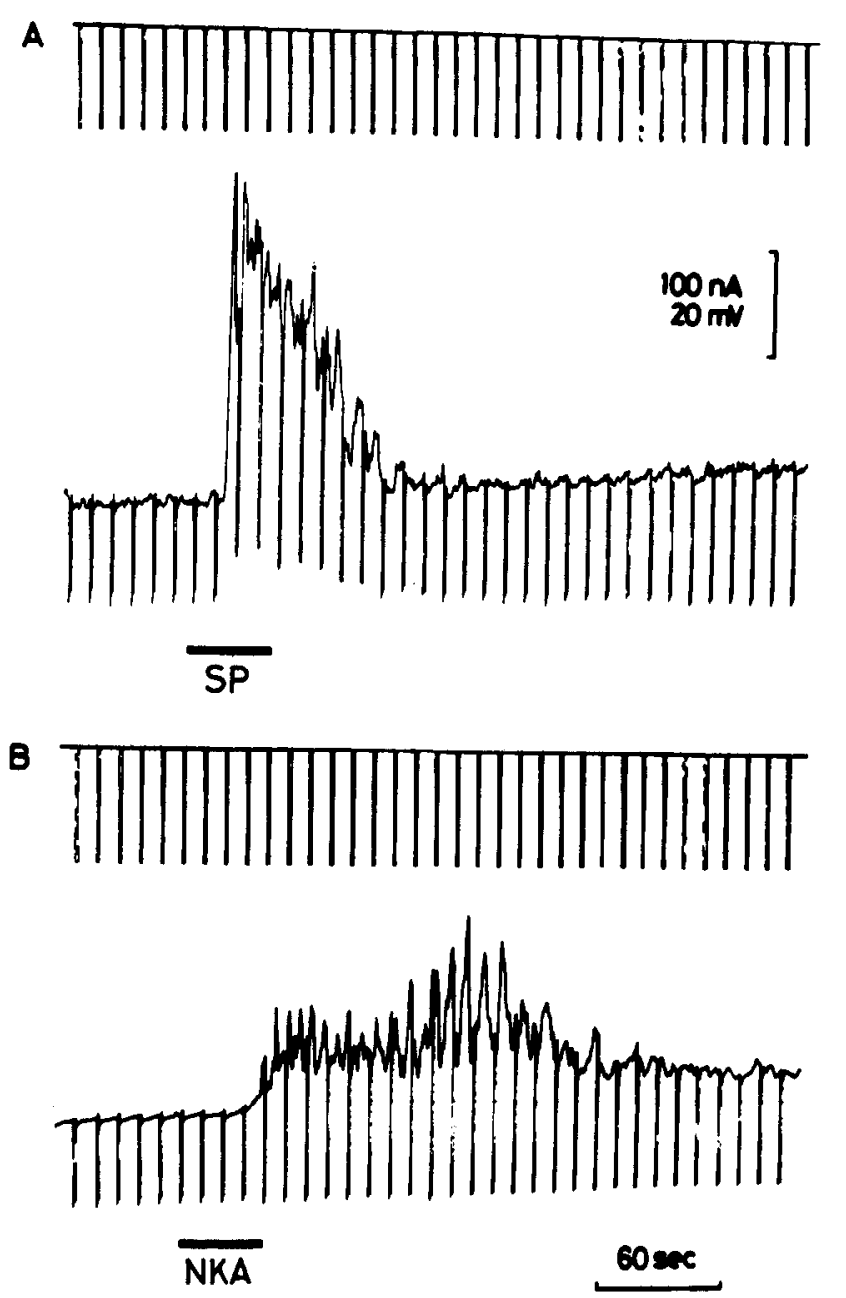

Figure 5. Responses of oocytes injected with rat brain mRNA $(A)$ and bovine stomach mRNA $(B)$ to SP $(A ; 4 \mu \mathrm{M})$ and NKA $(B ; 4 \mu \mathrm{M})$. Responses were recorded at a holding potential of $0 \mathrm{mV}$ in Ringer's solution. Upper traces, membrane potential, indicating that downward deflections correspond to hypcrpolarization. Lower traces, membrane current, indicating that upward deflections correspond to outward currents. Before and after the drug application, the holding potential was altered to about $-20 \mathrm{mV}$ for $1 \mathrm{sec}$ every $10 \mathrm{sec}$ (vertical pulses). One oocyte $(A)$ was incubated for $5 \mathrm{~d}$, the other $(B)$ for $3 \mathrm{~d}$ after the microinjection.

than those observed before drug application, and the $2 \mathrm{I}-\mathrm{V}$ curves intersected at about $-24 \mathrm{mV}$ in this particular case (Fig. $6 B$, arrowhead). Thus, electronic subtraction of the control I$\mathrm{V}$ curve from the SP I-V curve gave the membrane currents induced by SP as a function of the membrane potential (Fig. $6 C$ ), showing the reversal potential (arrowhead).

Figure 7 shows the reversal potentials of the responses to SP (open circles) and 5-HT (filled circles) recorded from an oocyte injected with rat brain mRNA. The reversal potentials of the 2 responses were indistinguishable (Fig. 7, arrow; Table 1A) and agreed with the value $(-24 \mathrm{mV})$ previously reported for 5-HT responses induced in oocytes (Gundersen et al., 1983). Since this reversal potential is similar to the chloride equilibrium potential in oocytes (Kusano et al., 1982), $\mathrm{Cl}^{-}$has been suggested as being the major ion involved in activation of 5-HT receptors translated in oocytes (Gundersen et al., 1983, 1984a). When two-thirds of external $\mathrm{Cl}^{-}$were replaced with isethionate ions, the reversal potentials of both the SP (Fig. 7, open circles) and 

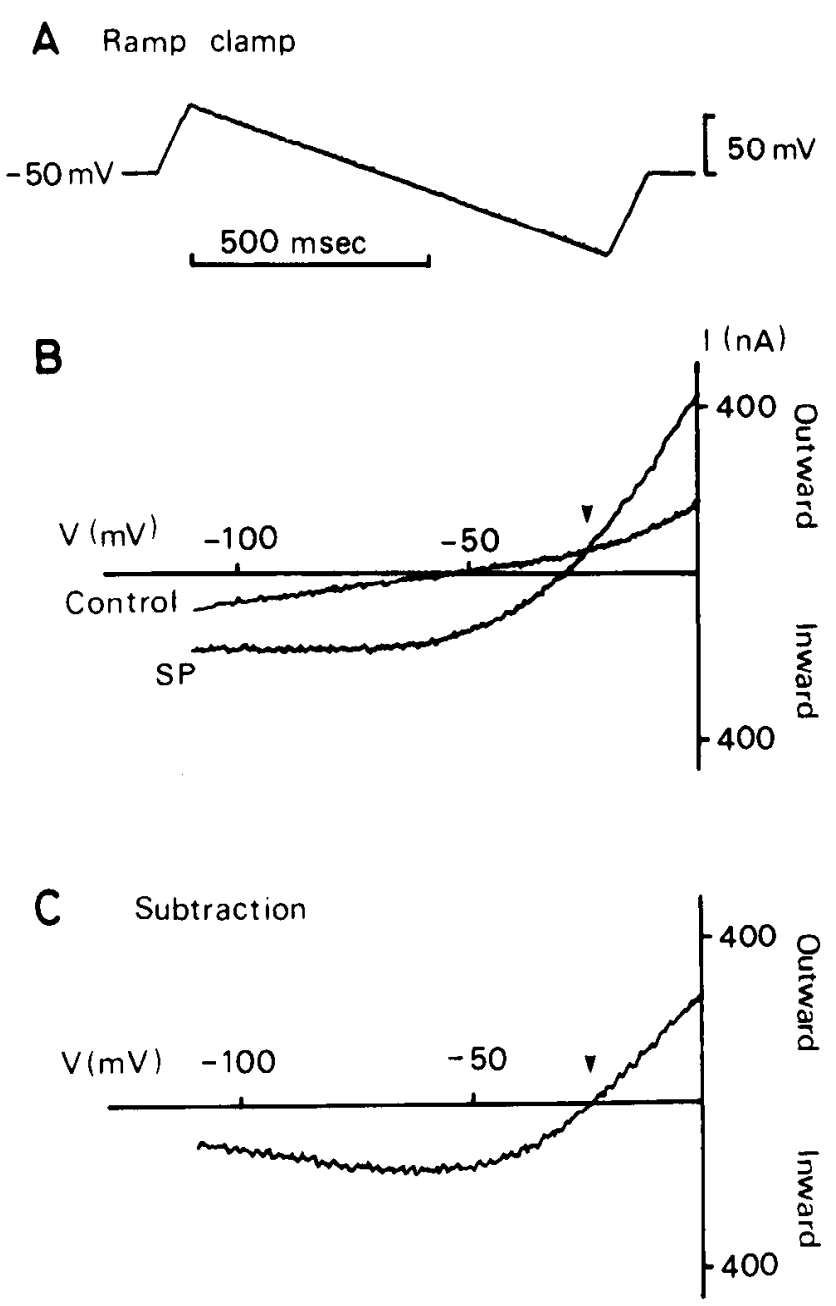

Figure 6. Ramp voltage-clamp applied to an oocyte incubated for 3 $\mathrm{d}$ after the injection of rat brain mRNA. $A$, Membrane potential changes produced by a ramp command potential superimposed on a holding potential of $-50 \mathrm{mV}$. $B$, Changes in membrane current evoked by the ramp command potential applied before (Control) and during the response to SP $(4 \mu \mathrm{M})$. Arrowhead corresponds to the reversal potential of SP currents. $C$, Electronic subtraction of the control current from the SP current in B. Arrowhead, the reversal potential of SP currents.

5-HT (Fig. 7, filled circles) responses were shifted to more positive levels by about $17 \mathrm{mV}$ (Fig. 8A, arrow; Table 1B). Essentially the same reversal potentials were observed for the SP and 5-HT responses when two-thirds of external $\mathrm{NaCl}$ were substituted for by sucrose (Fig. $8 B$, arrow; Table $1 C$ ). These results show that activation of the tachykinin receptor induced by rat brain mRNA is associated with increased $\mathrm{Cl}^{-}$conductance, whereas the $\mathrm{Na}^{+}$conductance remains virtually unchanged during the SP response.

The ionic mechanism underlying the SP response was thus remarkably similar to that for the 5-HT response (Figs. 7, 8). Activation of 5-HT receptors in oocytes might be partly accompanied by a decrease in the $\mathrm{K}^{+}$conductance, in addition to increased $\mathrm{Cl}^{-}$conductance (Parker et al., 1985). To test this possibility, half of the $\mathrm{NaCl}$ in Ringer's solution was replaced with equimolar $\mathrm{KCl}$. Under these conditions, the reversal potentials of the 5-HT and SP responses (Table 1D) were not significantly different from those observed in Ringer's solution (Table 1A). Thus, there was no evidence for alterations in the

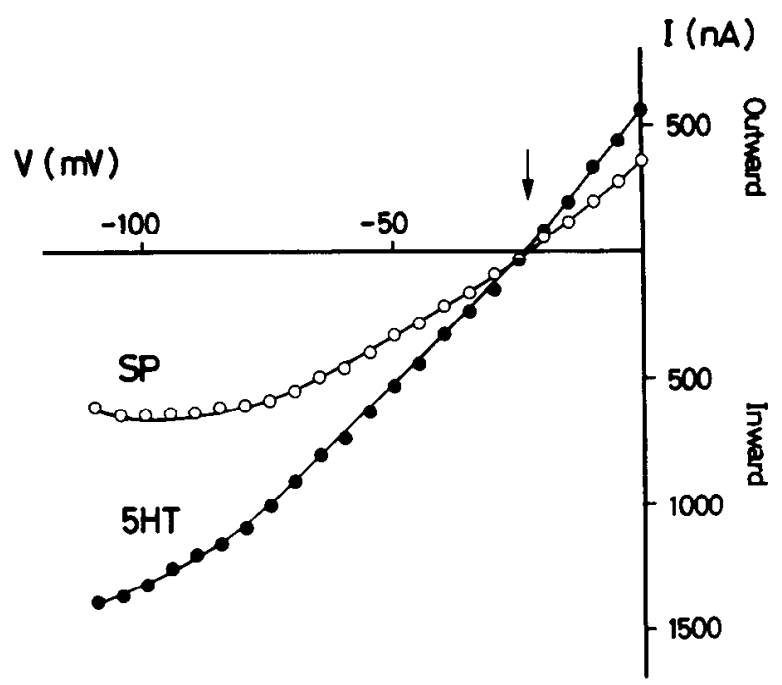

Figure 7. Membrane currents induced by SP (4 $\mu \mathrm{M})$ and 5-HT $(0.4$ $\mu \mathrm{M})$ as a function of the membranc potential. The measurements were made by the ramp voltage-clamp, as shown in Figure $6 \mathrm{C}$, from an oocyte incubated for $3 \mathrm{~d}$ after the injection of rat brain mRNA. Arrow indicates the reversal potentials of the SP and 5-HT currents observed in Ringer's solution.

$\mathrm{K}^{+}$conductance associated with activation of the 5-HT or SP receptor. It should be noted that the "ramp voltage-clamp" was executed near the peak of the SP or 5-HT response to analyze the major ionic mechanism. If these responses were accompanied by an additional small component that operated slowly, with a different ionic mechanism (Parker et al., 1986), the latter component would not have been detected by our analysis.

A similar procedure was adopted to examine the ionic mechanism responsible for activation of the tachykinin receplor induced by bovine stomach mRNA. The majority of these oocytes did not respond to $5-\mathrm{HT}$, so that the reversal potential of the tachykinin response could not be compared with that of the 5-HT response. However, since NKA responses could be elicited repeatedly in these oocytes, the effects of different solutions were examined in the same oocyte. Figure $8 C$ shows the $\mathrm{I}-\mathrm{V}$ relations of the NKA currents observed in an oocyte when the external $\mathrm{Cl}^{-}$(open circles) or $\mathrm{NaCl}$ (filled circles) concentration was reduced to onc-third of normal levels. In the 2 solutions, the reversal potential of the NKA current was approximately the same, about $-8 \mathrm{mV}$, as was the case for the tachykinin receptor induced by rat brain mRNA (Fig. $8, A, B$ ). As summarized in Table 1, the results obtained from oocytes injected with stomach mRNA again suggest that activation of the tachykinin receptor is accompanied primarily by an increase in the $\mathrm{Cl}^{-}$conductance. One puzzling behavior, however, was that the reversal potential of the NKA current observed in Ringer's solution (Table 1A) for oocytes injected with stomach mRNA was slightly, but significantly $(p<0.01)$, more negative than that of the SP current measured in oocytes injected with brain mRNA. At present, we have no adequate explanation for this discrepancy, nor is it certain whether this difference is genuine.

\section{Discussion}

In agreement with previous observations (Gundersen et al., 1983), the oocytes injected with exogenous mRNA were still responsive to 5-HT or SP even after incubation with actinomycin D to prevent the synthesis of mRNA. Furthermore, the presence or 


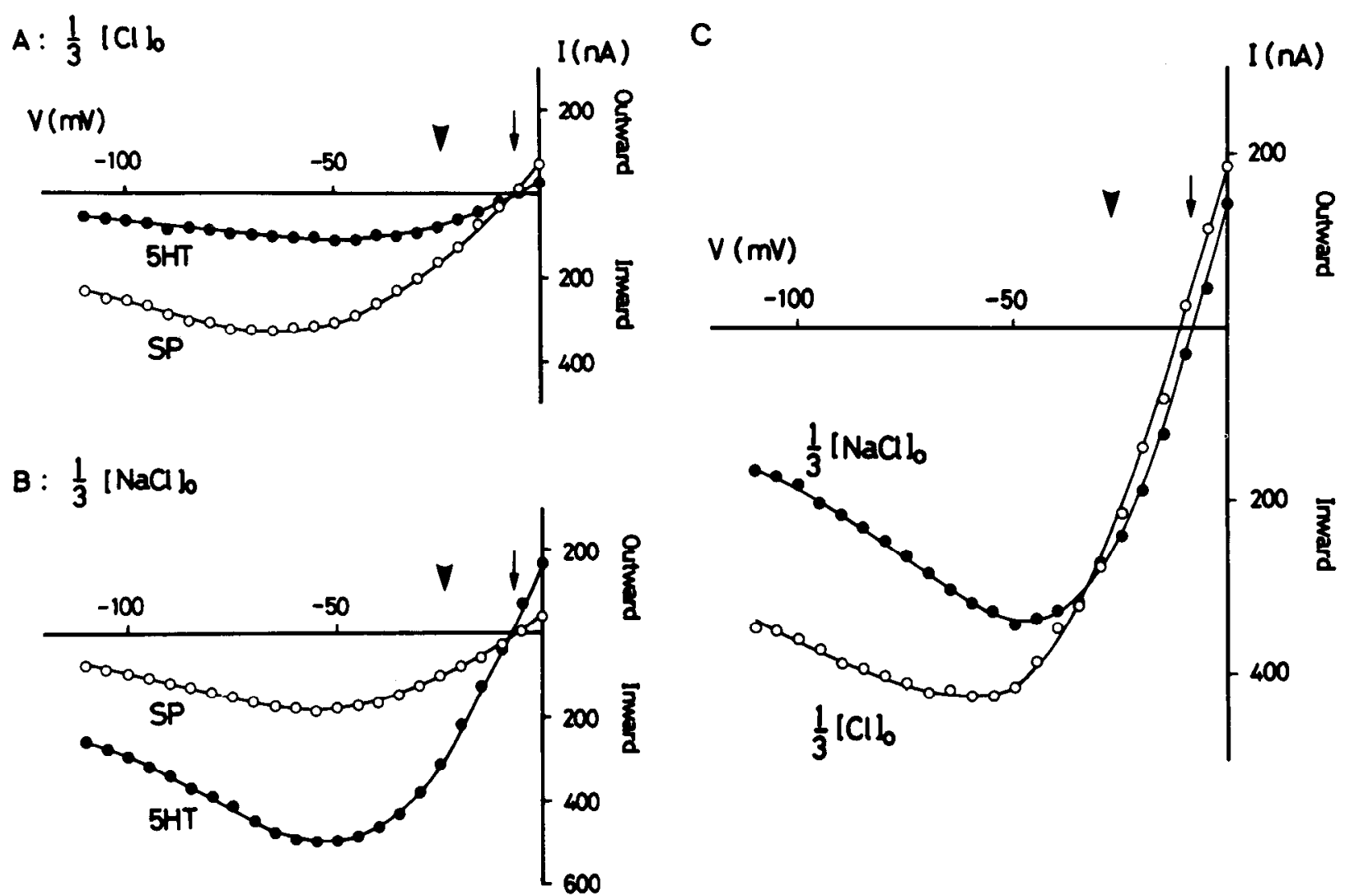

Figure 8. Membrane currents induced by SP $(4 \mu \mathrm{M})$ and $5-\mathrm{HT}(0.4 \mu \mathrm{M})$ in 2 different oocytes $(A, B)$ incubated for $3 \mathrm{~d}$ after the injection of rat brain mRNA, and by NKA $(4 \mu \mathrm{M})$ in an oocyte incubated for $3 \mathrm{~d}$ after the injection of bovine stomach mRNA $(C)$. The measurements were made as shown in Figure $6 C$, but two-thirds of $\mathrm{Cl}^{-}$in Ringer's solution were replaced with isethionate ions in $A$ and $C$, and two-thirds of $\mathrm{NaCl}$ in Ringer's solution were substituted by sucrose in $B$ and $C$. Arrows indicate the observed reversal potentials. Arrowheads, mean reversal potentials measured in Ringer's solution.

absence of 5-HT responses and the characteristics of tachykinin receptors depended upon the source of exogenous mRNA injected. Therefore, there was little doubt that the 5-HT or tachykinin receptors examined in the present study were newly synthesized by the injection of specific mRNA.

The tachykinin receptor induced by rat brain mRNA was distinguished from that formed by bovine stomach mRNA by a difference in their desensitization behavior. Also, for the tachykinin receptor induced by rat brain mRNA, PHY and SP were the most potent agonists, whereas these 2 agonists were the least potent group, and NKA was most potent for the receptor di- rected by bovine stomach mRNA. On the basis of the potency ranking of 6 tachykinin agonists, the former appears to correspond to a subtype currently classified as the NK-1 receptor, whereas the latter corresponds to the NK-2 receptor (Buck et al., 1984; Quirion, 1985; Lee et al., 1986). The latency and duration of the response elicited by the presumptive NK-2 receptor induced in oocytes injected with stomach mRNA were significantly longer than those evoked by the presumptive NK1 receptor induced by brain mRNA. In this context, it is intriguing to note that contractures of the rat duodenum evoked by NKA are longer in latency and duration than those produced

\section{Table 1. Reversal potentials of tachykinin and serotonin responses in different solutions}

\begin{tabular}{|c|c|c|c|c|c|}
\hline \multirow[b]{2}{*}{ Test drugs } & \multicolumn{3}{|l|}{ Rat brain } & \multicolumn{2}{|c|}{ Bovine stomach } \\
\hline & $\mathrm{SP}$ & NKA & 5-HT & SP & NKA \\
\hline A. Ringer & $\begin{array}{l}-23.5 \pm 2.7 \\
(n=11)\end{array}$ & $\begin{array}{l}-24.3 \pm 1.2 \\
(n=3)\end{array}$ & $\begin{array}{l}-23.9 \mp 3.5 \\
(n=17)\end{array}$ & $\begin{array}{l}-27.3 \pm 4.0 \\
(n=3)\end{array}$ & $\begin{array}{l}-27.6 \pm 4.3 \\
(n=14)\end{array}$ \\
\hline B. $1 / 3[\mathrm{Cl}]$ & $\begin{array}{l}-6.1 \pm 8.6 \\
(n=7)\end{array}$ & & $\begin{array}{l}-7.8 \pm 4.2 \\
(n=9)\end{array}$ & & $\begin{array}{l}-9.5 \pm 11.5 \\
(n=10)\end{array}$ \\
\hline C. $1 / 3[\mathrm{NaCl}]$ & $\begin{array}{l}-5.0 \pm 1.4 \\
(n=4)\end{array}$ & & $\begin{array}{l}-7.0 \pm 3.6 \\
(n=6)\end{array}$ & & $\begin{array}{l}-6.8 \pm 2.1 \\
(n=7)\end{array}$ \\
\hline D. $1 / 2[\mathrm{NaCl}]+1 / 2[\mathrm{KCl}]$ & $\begin{array}{l}-24.7 \pm 1.5 \\
(n=3)\end{array}$ & & $\begin{array}{l}-25.0 \pm 1.0 \\
(n=3)\end{array}$ & & $\begin{array}{l}-26.6 \pm 2.5 \\
(n=5)\end{array}$ \\
\hline
\end{tabular}


by SP (Nawa et al., 1984a). In the present study, the 2 types of receptors could be induced in the same expression system, depending on the source of exogenous mRNA injected. Therefore, the differences in the natures of the 2 receptors do not seem to be due to the possible posttranslational modification occurring at their destination tissues alone. However, it might be argued that the mRNA samples isolated from rat brain and bovine stomach may encode different accessory proteins, which, in turn, modify the properties of the same receptor molecule in a tissuespecific manner. If this were the case, the mRNA encoding the receptor molecule would be expected to be present in the fraction with the same sedimentation coefficient when the poly $(A)^{+}$RNA sample was extracted from the brain or peripheral tissues. Our preliminary observations suggest that the bovine stomach mRNA encoding the presumptive $\mathrm{NK}-2$ receptor is located in a more slowly sedimentating fraction than is the bovine brain (amygdaloid nucleus) mKNA coding for the presumptive NK-1 receptor. An expression study using further purification of mRNA is now under way.

In addition to NK-1 and NK-2 receptors, the existence of a receptor subtype specific for NKB has also been suggested (NK3: Buck et al., 1984; Laufer et al., 1985; Quirion, 1985; Lee et al., 1986). This type of receptor was not encountered in the present study. However, it is possible that the response evoked by this receptor might have been masked by large responses produced by other tachykinin receptors. Similarly, it was not certain whether the injection of brain mRNA or stomach mRNA directed the expression of only one type of tachykinin receptor exclusively or whether the expression of a particular receptor type became relatively dominant, depending on the source of mRNA injected.

The nature of the desensitization or tachyphylactic behavior of tachykinin responses was not clear. Recently, inositol trisphosphate has been suggested as being involved in the generation of $\mathrm{Cl}^{-}$currents triggered by acetylcholine (Oron et al., 1985), 5-HT, or other neurotransmitters (Parker et al., 1985, 1986). It is possible that the tachyphylaxis may be manifested by depletion of the available intracellular mediator. However, tachyphylaxis was clearly more prominent in oocytes injected with brain mRNA than in those injected with stomach mRNA. Thus, the degree of tachyphylaxis appears to depend upon the receptor type. Furthermore, in oocytes injected with brain mRNA, the responses to potent agonists (PHY, SP, NKA) were smaller at high $(0.4 \mu \mathrm{M})$ than at low $(0.1 \mu \mathrm{M})$ doses. If the response magnitude were limited by the amount of available intracellular mediator, the responses elicited by an agonist at doses higher than a certain concentration would be expected to approach the same maximal level. Depression of the tachykinin response at high doses suggests that the degree of tachyphylaxis depends upon the ligand concentration. Therefore, it is likely that this tachyphylaxis occurs at the receptor level, although its mechanism remains unknown. Again, it is possible that some accessory protein encoded by a particular mRNA present in the poly $(\mathrm{A})^{+}$RNA sample isolated from rat brain might induce such tachyphylactic behavior by the receptor.

As was the case for activation of 5-HT receptors (Gundersen et al., 1983, 1984a; Parker et al., 1985), activation of tachykinin receptors was also associated primarily with an increase in the $\mathrm{Cl}^{-}$conductance. The $\mathrm{I}-\mathrm{V}$ relation of the 5-HT- or tachykinininduced currents was strikingly similar to that of $\mathrm{Ca}^{2+}$-activated $\mathrm{Cl}^{-}$currents (Miledi, 1982; Barish, 1983), showing rectification by hyperpolarization beyond about $-50 \mathrm{mV}$ (Miledi and Parker, 1984). A similar relation has been observed for glycineactivated $\mathrm{Cl}^{-}$currents in oocytes injected with human brain mRNA (Gundersen et al., 1984b). This rectification of $\mathrm{Cl}^{-}$currents has been attributed to a shortening of the channel open time by hyperpolarization (Gundersen et al., 1986).

The ionic mechanisms responsible for activation of the 2 subtypes of tachykinin receptors were basically the same. The explanation for a slight difference between the reversal potentials of tachykinin currents in the 2 receptors remains to be clarified. It should be noted that the ionic mechanisms observed in the present study are unique to the oocyte in which the tachykinin receptors are expressed. Since the cellular second messenger associated with activation of the receptor would be different in the oocyte from that in the neurons in the vertebrate, the ionic mechanisms analyzed in the present study cannot be generalized.

\section{References}

Aviv, H., and P. Leder (1972) Purification of biologically active globin messenger RNA by chromatography on oligothymidylic acid-cellulose. Proc. Natl. Acad. Sci. USA 69: 1408-1412.

Barish, M. E. (1983) A transient calcium-dependent chloride current in the immature Xenopus oocyte. J. Physiol. (Lond.) 342: 309-325.

Barnard, E. A., R. Miledi, and K. Sumikawa (1982) Translation of cxogenous messenger RNA coding for nicotinic acetylcholinc receptors produces functional receptors in Xenopus oocytes. Proc. R. Soc. Lond. [Biol.] 215: 241-246.

Barth, L. G., and L. J. Barth (1959) Differentiation of cells of the Rana pipiens gastrula in unconditioned medium. J. Embryol. Exp. Morphol. 71: $210-222$.

Buck, S. H., E. Burcher, C. W. Shultz, W. Lowenberg, and T. L. O'Donohue (1984) Novel pharmacology of substance K-binding sites: A third type of tachykinin receptor. Science 226: 987-989.

Chirgwin, J. M., A. E. Przybyla, R. J. MacDonald, and W. J. Rutter (1979) Isolation of biologically active ribonucleic acid from sources enriched in ribonuclease. Biochemistry 18: 5294-5299.

Dascal, N., E. M. Landau, and Y. Lass (1984) Xenopus oocyte resting potential, muscarinic responses and the role of calcium and guanosine 3',5'-cyclic monophosphate. J. Physiol. (Lond.) 352: 551-574.

Erspamer, V. (1981) The tachykinin peptide family. Trends Neurosci. 4: $267-269$.

Gundersen, C. B., R. Miledi, and I. Parker (1983) Serotonin receptors induced by exogenous messenger RNA in Xenopus oocytes. Proc. R. Soc. Lond. [Biol.] 219: 103-109.

Gundersen, C. B., R. Miledi, and I. Parker (1984a) Messenger RNA from human brain induces drug- and voltage-operated channels in Xenopus oocytes. Nature 308: 421-424.

Gundersen, C. B., R. Miledi, and I. Parker (1984b) Properties of human brain glycine receptors expressed in Xenopus oocytes. Proc. R. Soc. Lond. [Biol.] 221: 235-244.

Gundersen, C. B., R. Miledi, and I. Parker (1986) Voltage dependence of human brain glycine receptor-channels in Xenopus oocytes. J. Physiol. (Lond.) 377: 40P.

Harada, Y., T. Takahashi, M. Kuno, K. Nakayama, and S. Nakanishi (1986) Expression of substance P receptors in Xenopus oocytes by injections of poly(A) RNA extracted from the rat brain. Proc. IUPS 30:64.

Harmer, A., J., A. Armstrong, J. C. Pascall, K. Chapman, R. Rosie, A. Curtis, J. Going, C. R. W. Edwards, and G. Fink (1986) cDNA sequence of human $\beta$-preprotachykinin, the common precursor to substance $P$ and neurokinin A. FEBS Lett. 208: 67-72.

Hökfelt, T., J. O. Kellerth, G. Nilsson, and B. Pernow (1975) Experimental immunohistochemical studies on the localization and distribution of substance $P$ in cat primary sensory neurons. Brain Res. 100: $235-252$.

Hunter, J. C., and J. E. Maggio (1984) Pharmacological characterization of a novel tachykinin isolated from mammalian spinal cord. Eur. J. Pharmacol. 97: 159-160. 
Kangawa, K., N. Minamino, A. Fukuda, and H. Matsuo (1983) Neuromedin $\mathrm{K}$ : A novel mammalian tachykinin identified in porcine spinal cord. Biochem. Biophys. Res. Commun. 114: 533-540.

Kimura, S., M. Okada, Y. Sugita, I. Kanazawa, and E. Munekata (1983) Novel neuropeptides, neurokinin $\alpha$ and $\beta$, isolated from porcine spinal cord. Proc. Jpn. Acad. Sci. [Biol.] 59: 101-104.

Kusano, K., R. Miledi, and J. Stinnakre (1982) Cholinergic and catecholaminergic receptors in the Xenopus oocyte membrane. J. Physiol. (Lond.) 328: 143-170.

Laufer, R., U. Wormser, Z. Y. Friedman, C. Gilon, M. Chorev, and Z. Selinger (1985) Neurokinin B is a preferred agonist for a neuronal substance $P$ receptor and its action is antagonized by enkephalin. Proc. Natl. Acad. Sci. USA 82: 7444-7448.

Lee, C.-M., L. L. Iversen, M. R. Hanley, and B. E. B. Sandberg (1982) The possible existence of multiple receptors for substance P. Naunyn Schmiedebergs Arch. Pharmacol. 318: 281-287.

Lee, C.-M., N. J. Campbell, B. J. Williams, and L. L. Iversen (1986) Multiple tachykinin binding sites in peripheral tissues and in brain. Eur. J. Pharmacol. 130: 209-217.

Miledi, R. (1982) A calcium-dependent transient outward current in Xenopus laevis oocytes. Proc. R. Soc. Lond. [Biol.] 215: 491-497.

Miledi, R., and I. Parker (1984) Chloride current induced by injection of calcium into Xenopus oocytes. J. Physiol. (Lond.) 357: 173-183.

Miledi, R., and K. Sumikawa (1982) Synthesis of cat muscle acetylcholine receptors by Xenopus oocytes. Biomed. Res. 3: 390-399.

Nakanishi, S. (1986) Structure and regulation of the preprotachykinin gene. Trends Neurosci. 9: 41-44.

Nawa, H., T. Hirose, H. Takashima, S. Inayama, and S. Nakanishi (1983) Nucleotide sequences of cloned cDNA for two types of bovine brain substance $P$ precursor. Nature 306: 32-36.

Nawa, H., M. Doteuchi, K. Igano, K. Inouye, and S. Nakanishi (1984a)
Substance K: A novel mammalian tachykinin that differs from substance $P$ in its pharmacological profile. Life Sci. 34: 1153-1160.

Nawa, H., H. Kotani, and S. Nakanishi (1984b) Tissue-specific generation of two preprotachykinin mRNAs from one gene by alternative RNA splicing. Nature 312: 729-734.

Oron, Y., N. Dascal, E. Nadler, and M. Lupu (1985) Inositol 1,4,5trisphosphate mimics muscarinic response in Xenopus oocytes. Nature 313: 141-143.

Otsuka, M., S. Konishi, and T. Takahashi (1975) Hypothalamic substance $\mathrm{P}$ as a candidate for transmitter of primary afferent neurons. Fcd. Proc. 34: 1922-1928.

Parker, I., C. B. Gundersen, and R. Miledi (1985) Intracellular $\mathrm{Ca}^{2+}$ dependent and $\mathrm{Ca}^{2+}$-independent responses of rat brain serotonin receptors transplanted to Xenopus oocytes. Neurosci. Res. 2: 491496.

Parker, I., K. Sumikawa, and R. Miledi (1986) Neurotensin and substance $\mathrm{P}$ receptors expressed in Xenopus oocytes by messenger RNA from rat brain. Proc. R. Soc. Lond. [Biol.] 229: 151-159.

Quirion, R. (1985) Multiple tachykinin receptors. Trends Neurosci. 8: $183-185$.

Sumikawa, K., I. Parker, T. Amano, and R. Miledi (1984a) Separate fractions of mRNA from Torpedo electric organ induce chloride channels and acetylcholine receptors in Xenopus oocytes. EMBO J. 3: 2291-2294.

Sumikawa, K., I. Parker, and R. Milcdi (1984b) Partial purification and functional expression of brain mRNAs coding for neurotransmitter receptors and voltage-operated channels. Proc. Natl. Acad. Sci. USA $81:$ 7994-7998.

Takahashi, T., and M. Otsuka (1975) Regional distribution of substance $\mathbf{P}$ in the spinal cord and nerve roots of the cat and the effect of dorsal root section. Brain Res. 87: 1-11. 